\title{
Changes in petrophysical properties of the stone surface due to past conservation treatments in archaeological sites of Merida (Spain).
}

\author{
Perez-Ema, Natalia ${ }^{1,2,3}$, Alvarez de Buergo, Monica ${ }^{2}$, Bustamante, Rosa ${ }^{3}$ and \\ Miguel Gomez-Heras ${ }^{1,2,3}$ \\ 1 CEI Campus Moncloa. UCM-UPM. Edif. Real Jardín Botánico Alfonso XIII, Avda. Complutense, s/n 28040 Madrid, Spain \\ 2 Instituto de Geociencias IGEO (CSIC, UCM). C/ José Antonio Nováis, 12. 28040 Madrid, Spain. \\ 3 Escuela Tecnica Superior de Arquitectura, Universidad Politecnica de Madrid. Avda. Juan de Herrera, 4. 28040 Madrid, Spain.
}

Petrophysical properties, such as porosity, permeability, density or anisotropy determine the alterability of stone surfaces from archaeological sites, and therefore, the future preservation of the material. Others, like superficial roughness or color, may point out changes due to alteration processes, natural or man-induced, for example, by conservation treatments.

The application of conservation treatments may vary some of these properties forcing the stone surface to a re-adaptation to the new conditions, which could generate new processes of deterioration. In this study changes resulting from the application of consolidating and hydrophobic treatments on stone materials from the Roman Theatre (marble and granite) and the Mitreo's House (mural painting and mosaics), both archaeological sites from Merida (Spain), are analyzed. The use of portable field devices allows us to perform analyses both on site and in laboratory, comparing treated and untreated samples. Treatments consisted of synthetic resins, consolidating (such as tetraethoxysilane TEOS) and hydrophobic products. Results confirm that undesirable changes may occur, with consequences ranging from purely aesthetic variations to physical, chemical and mechanical damages. This also permits us to check limitations in the use of these techniques for the evaluation of conservation treatments.

Keywords: Archaeological sites, stone, marble, granite, Conservation, Treatments, Petrophysical properties, Merida 


\section{Introduction}

The research project in which this study is included is focused on the analysis of the effects of conservation treatments applied on stone material from archaeological sites, in terms of effectiveness, durability and alteration processes derived from its application. Since alteration processes depends greatly on the interaction between the surface and the surrounding environment, either burial or aerial, the analysis of petrophysical properties is an essential task to characterize the material, as well as for the reasoned proposal of preservation treatments, but also in order to evaluate their effects.

The archaeological city of Merida was listed as World Heritage site by UNESCO in 1993 and includes several monumental remains from the Roman period. The sites in which this study is focused are the Roman Theater, inaugurated in 15 B.C, and Mitreo's House, built in the late first or early second century.

Review of scientific literature regarding evaluation of conservation treatments for stone material allows us to state that: 1. Most of the studies are based on fresh/unaltered stone materials on which a specific treatment is tested (mainly consolidating and hydrophobic products), subjected, later on, to accelerated ageing tests; 2 . It is mostly based on laboratory studies, being very different working on site, with original and specific materials and alterations; 3 . These studies are focused on historic built heritage or outdoor sculpture, and very rarely on archaeological sites. Some negative effects of conservation treatments are already well known, such as, for example, the photo-oxidative degradation of synthetic resins (Favaro et al. 2006; Chiantore and Lazzari 2001) frequently used in the restoration of wall paintings. In the case of ethyl silicate there are studies analyzing its limited effectiveness caused by the presence of water (Rodrigues da Costa and Delgado Rodrigues 2011), or superficial alteration such as discoloration, darkening and brightness changes. Special attention has been paid on hydrophobic treatments in the last years, taking into account that in most of the alteration phenomena the water is present. These treatments can be extremely aggressive in the case of archaeological stone showing physical and mechanical damages, as well as color changes (Fort el al. 2000). The presence of salts inside the stone materials when applying superficial treatments, which act as impermeable barriers, can also lead to accelerated decay (Varas et al. 2007).Changes in the stone surface could lead to general degradation of the material; in this sense the superficial roughness and color are key parameters. The roughness affects the weatherability of the material against external agents; the rougher texture leads to a higher reactive surface area, moreover it promotes the deposition of particles from environment and the water retention, favoring the formation of crusts, soiling and salt efflorescences (Alvarez de Buergo et al. 2011). Color changes, besides aesthetic disturbance, may indicate also chemical and physical alterations (Fort et al. 2000). 


\section{Methodology and techniques}

The review of conservative interventions carried out in both selected archaeological sites permits the selection of treated and untreated areas where developing comparative analysis through the use of portable and non destructive equipments, listed below. On the other hand several samples of the original stone material were collected on site; marble (different types and colors) and granite from the Roman Theater, and wall painting fragments from the Mitreo's House. In addition to portable techniques, in the IGEO's Petrophysics laboratory it is possible to complement on site measurement with some other techniques, always comparing pre- and post-treatment.

Portable field devises used are as follows:

- Measurements of the propagation velocity of ultrasound (Pundit equipment)

- Optical surface roughnessmeter (TRACEiT, Innowep GMBH)

- Raman spectrometer (Inspector Raman Delta Nu)

- Hardness tester (Equotip 3)

- Spectrophotometry color measurement (Minolta CM-700d/600D).

- Infrared Termography (ThermaCAM $\left.{ }^{\mathrm{TM}} \mathrm{B} 4\right)$

Laboratory tests:

- Scanning electron microscopy SEM and element microanalysis (EDS)

- Mercury intrusion porosimetry (MIP)

- Determination of hydric properties by Nuclear Magnetic Resonance NMR, Contact Angle test (static angle), or water saturation and capillarity tests.

\section{Results}

\subsection{Measurements on site}

Regarding the Roman Theater, all measurements were focused on the evaluation of last general intervention, carried out on the Front Stage in 1996.

Treatments on marble were mainly based on chemical cleaning, punctual consolidation with ethyl silicate and a general protection with hydrophobic products.

Most of the outcomes in this case show differential values mainly due to the state of preservation. Thus, the treated areas were altered areas, and therefore show lower levels of, for instance, superficial hardness (Table 1), color $\left(\Delta E^{*}=2.9^{1}\right)$ or water absorption (Table 2). In these cases laboratory tests and measurements on recently applied treated areas are imperative in order to evaluate such parameters in terms of effectiveness. The difference between roughness values, however, is very high, considering treated area, disaggregated, and the unaltered one (Table

\footnotetext{
${ }^{1}$ Based on CIELab system, where $\Delta \mathrm{E}^{*}=\sqrt{ }(\Delta \mathrm{L} *)^{2}+\left(\Delta \mathrm{a}^{*}\right)^{2}+(\Delta \mathrm{b} *)^{2}$
} 
3). Results obtained with infrared termography revealing, for example, different thermal behavior comparing treated and untreated parts of the same marble piece from the basement (Figures 1,2).

\begin{tabular}{|c|c|c|}
\hline & Treated areas & Untreated areas \\
\hline Grey marble - columns & $392 \mathrm{HLD}( \pm 50)$ & $522 \mathrm{HLD}( \pm 31)$ \\
\hline White marble - cornices & $494 \mathrm{HLD}( \pm 58)$ & $544 \operatorname{HLD}( \pm 36)$ \\
\hline \multicolumn{3}{|c|}{ Table 1: Average values for superficial hardness (Leeb hardness scale) } \\
\hline White marble - cornices & $\mathrm{WA}_{\mathrm{LP}}=0.0004$ & $\mathrm{WA}_{\mathrm{LP}}=0.0000$ \\
\hline
\end{tabular}

\begin{tabular}{|c|c|c|}
\hline White marble - cornices & $\mathrm{Rz}=8.7( \pm 10)$ & $\mathrm{Rz}=21.08( \pm 19)$ \\
\hline Table 3: Average values for superficial roughness measured on fragment A2cor31 \\
\hline
\end{tabular}

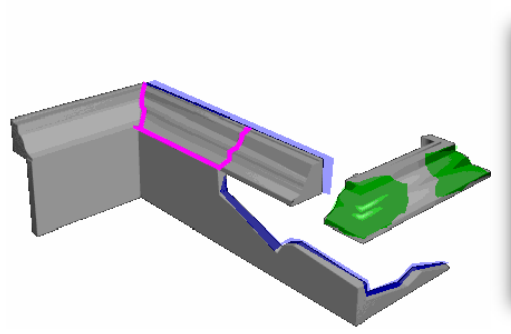

Fig. 1: Application of TEOS is in green color (Source: Agora S.L)

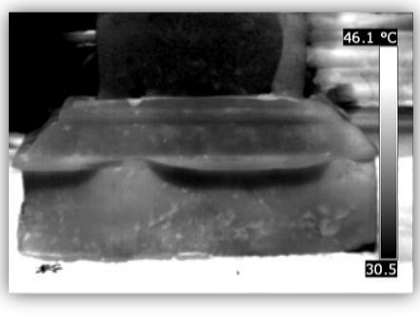

Fig. 2: Image obtained with an IR Termographic camera

In the case of the Mitreo's House, interventions are developed continuously since the 80 's. Products used are mainly synthetic resins for the consolidation of the wall paintings and mosaics, but also, though less regularly, TEOS.

Measurements carried out on wall painting show different degree of internal cohesion (Table 4), as well as changes in color parameters in the Cosmologic Mosaic with a $\Delta \mathrm{E}^{*}$ value of 7 . Regarding hardness measurements the difficulty lays on the way the panel in attached to the mural support, not providing representative outcomes unless these conditions are identical for the whole panel extension. In most of cases the edges of the panels were consolidated with plaster, leading to a differential level of adhesion to the support in the center of the panel, which has a poor adhesion, with respect to the wall, and the outer consolidated parts.

\begin{tabular}{|c|c|}
\hline Treated area & Untreated area \\
\hline $2182 \mathrm{~m} / \mathrm{s}$ & $1611 \mathrm{~m} / \mathrm{s}$ \\
\hline \multicolumn{2}{|c|}{ Table 4: Values for ultrasound measurements, by indirect method, on Mitreo's House } \\
\hline
\end{tabular}

\footnotetext{
${ }^{2}$ Based on CEN/TC 346 N. 244 protocol for the evaluation of water-repellents
} 


\subsection{Laboratory tests}

Given limitations for comparative assessment on site, laboratory tests are essential. Treatments applied on laboratory reproduce those ones documented on each site, analyzing specimens before and after application and analyzing changes on the materials surface.

The results from the contact angle test show high efficiency for all cases when assessing hydrophobicity. Nevertheless, mercury intrusion porosity tests prove that, although an overall decrease of porosity, treatments change the preexisting balance between macro and microporosity, increasing the first one and decreasing the second one in the case of marble.

Tests carried out on fragments of wall painting show an increase in superficial microroughness (Table 5) as well as remarkable changes in color parameters in the case of ethyl silicate treatment $\left(\Delta \mathrm{E}^{*}=10.4\right)$.
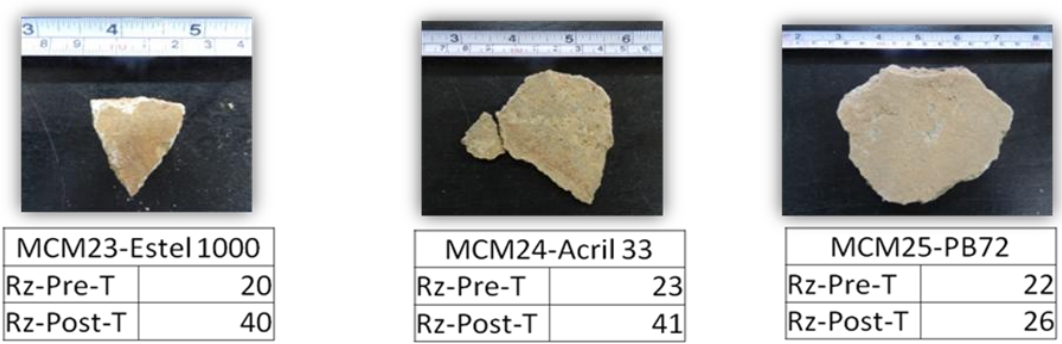

Table 5: Changes in superficial roughness on wall painting fragments from Mitreo's

House

\section{Conclusions}

The analysis of the effects of conservation treatments should be based, as far as possible, on in situ measurements, in order to evaluate these effects in its original context. This involves some difficulties, first the access to accurate information about previous interventions, the use of portable and non-destructive techniques, then measurements must be numerous to be representative, but we must also know the limits of each technique, as the multitude of variables that act on outdoor environment are large and heterogeneous.

Regarding durability of treatments, SEM analyses show that there are still remnants and traces of treatment on marbles from the Theater, but its effectiveness has not been proved. Treated areas of marbles are currently disaggregated, affected by sugaring. In this case there are few differences between treated and untreated areas, and it cannot be deduced that, when existing, they are caused by the treatment. Specimens studied on laboratory clearly show changes on the surface of all stone material treated. All of them will be placed in its original context in order to moni- 
tor changes periodically during at least 1 year and compare these results to those obtained from in situ measurements.

\section{References}

ALVAREZ DE BUERGO, M., VÁZQUEZ-CALVO, M.C., FORT, R. (2011). The measurement of surface roughness to determine the suitability of different methods for stone cleaning. Geophysical Research Abstracts, 13, EGU2011-6443. CHIANTORE, O. \& LAZZARI, M. (2001). Photo-oxidative stability of paraloid acrylic protective polymers. Polymer 42: 17-27.

FAVARO, M., MENDICHI, R., OSSOLA, F., RUSSO, U., SIMON, S., TOMASIN, P. \& VIGATO, P.A. (2006) "Evaluation of polymers for conservation treatments of outdoor exposed stone monuments. Part I: Photo-oxidative weathering", Polymer Degradation and Stability, vol. 91, no.12, pp. 3083-3096.

FORT, R., LOPEZ DE AZCONA, M.C., MINGARRO, F., ALVAREZ DE BUERGO, M. \& RO RIGUEZ, J. (2000). A comparative study of the efficiency of siloxanes, methacrylates and microwax-based treatments applied to the stone materials of the Royal Palace of Madrid, Spain. In V. Fassina (ed.) $9^{\text {th }}$ International congress on deterioration and conservation of stone. Amsterdam: Elsevier.

RODRIGUES DA COSTA AND DELGADO RODRIGUES (2011). The Effect of Water on the Durability of Granitic Materials Consolidated With Ethyl Silicates. Adhesives and Consolidants in Conservation: Research and Application. CCI Symposium-Ottawa (Canada).

VARAS, M.J., ALVAREZ DE BUERGO, M. \& FORT, R. (2007). The influence of past protective treatments on the deterioration of historic stone façades: a case study. Studies in Conservation 52: 110-125.

\section{Acknowledgements}

This research was supported by the PICATA program from Campus of International Excellence of Moncloa. Our acknowledgements to GEOMATERIALES programme (S2009-MAT1629) within Instituto de Geociencias (CSIC, UCM), to AIPA programme (ETSAM, Polytechnic University of Madrid) and to the Research Group financed by the Complutense University of Madrid "Alteration and Conservation of heritage stone materials" (ref. 921349). We thank the Consorcio de la Ciudad Monumental de Merida, as well as the Museo Nacional de Arte Romano de Merida, for its collaboration in this research. 